\title{
Use of Vasopressors Increases the Risk of Mortality in Severe Traumatic Brain Injury: A Nationwide Retrospective Cohort Study in Japan
}

Sanae Hosomi ( $\nabla$ s-hosomi@hp-emerg.med.osaka-u.ac.jp )

Osaka University Hospital: Osaka Daigaku Igakubu Fuzoku Byoin

Tomotaka Sobue

Osaka University: Osaka Daigaku

Tetsuhisa Kitamura

Osaka University: Osaka Daigaku

Atsushi Hirayama

Osaka University: Osaka Daigaku

Hiroshi Ogura

Osaka University: Osaka Daigaku

Takeshi Shimazu

Osaka University: Osaka Daigaku

\section{Research}

Keywords: Cerebral perfusion, cognitive dysfunction, mortality, resuscitation, traumatic brain injury, vasopressor.

Posted Date: January 7th, 2021

DOI: https://doi.org/10.21203/rs.3.rs-140000/v1

License: () (i) This work is licensed under a Creative Commons Attribution 4.0 International License. Read Full License 


\section{Abstract}

Background: Pharmacological elevation of blood pressure is frequently incorporated in severe traumatic brain injury (TBI) management algorithms. However, there is limited evidence on prevalent clinical practices regarding resuscitation for severe TBI using vasopressors. We conducted a nationwide retrospective cohort study to determine the association between the use of vasopressors and mortality following discharge from hospital in patients with severe $\mathrm{TBI}$, and to determine whether the use of vasopressors affects emergency department mortality or the occurrence of cognitive dysfunction.

Methods: Data were collected between January 2004 and December 2018 by the Japanese Trauma Data Bank, which includes data from 272 emergency hospitals in Japan. Adults aged $\geq 16$ years with severe TBI, without other major injuries, were examined. A severe TBI was defined based on the Abbreviated Injury Scale code and a Glasgow Coma Scale score of 3-8 on admission. Multivariable and propensity score matching analyses were performed. Statistical significance was assessed using a $95 \% \mathrm{Cl}$.

Results: In total, 10,284 patients were eligible for analysis, with 650 patients (6.32\%) included in the vasopressor group and 9,634 patients (93.68\%) included in the non-vasopressor group. The proportion of deaths on hospital discharge was higher in the vasopressor group than in the non-vasopressor group (81.69\% [531/650] vs. 40.21\% [3,874/9,634]). This finding was confirmed by multivariable logistic regression analysis (adjusted odds ratio [OR], 5.71; 95\% confidence interval [Cl]: 4.56-7.16). Regarding propensity score-matched patients, the proportion of deaths on hospital discharge remained higher in the vasopressor group than in the non-vasopressor group (81.66\% [530/649] vs. 50.69\% [329/649]) (OR, 4.33; 95\% Cl: 3.37-5.57). The vasopressor group had a higher emergency department mortality rate than the non-vasopressor group (8.01\% [52/649] vs. 2.77\% [18/649]) (OR, 3.05; 95\% $\mathrm{Cl}$ : 1.77-5.28). There was no reduction in complications of cognitive disorders in the vasopressor group (5.39\% [35/649] vs. 5.55\% [36/649]) (OR, 0.97; 95\% Cl: 0.60-1.57).

Conclusions: In this population, the use of vasopressors for severe TBI was associated with higher mortality on hospital discharge. Our results suggest that vasopressors should be avoided in most cases of severe TBI.

\section{Background}

Severe traumatic brain injury (TBI) is a leading cause of death and disability in people of all generations worldwide [1-3] and is associated with high economic and social costs [4]. Severe TBI is characterized by a primary insult that involves the initial mechanical force of impact and results in loss of brain tissue and neuronal cell death. Secondary injury occurs in the minutes and hours following the primary injury. Although little can be done to reverse the primary brain damage, secondary brain injury due to dysregulation of cerebral blood flow is potentially preventable. Therefore, acute management of patients after severe TBI aims to minimize secondary brain injury by maintaining cerebral perfusion pressure (CPP), defined as the difference between mean blood pressure and intracranial pressure [5-8].

Blood pressure control is the mainstay of therapy for several acute cerebral disorders, both in the early emergent phase immediately after brain injury and in the subsequent intensive care unit phase [9]. Hypotension in the acute phase of severe TBI is a key factor associated with poor clinical outcome [7-9]. Although vasopressors are considered to be harmful in trauma patients, in cases of a hemorrhagic shock state [10], pharmacological elevation of blood pressure is frequently incorporated in severe TBI management algorithms aimed at preventing or treating cerebral ischemia caused by reduced CPP $(<60 \mathrm{mmHg})[5]$. However, there is limited evidence on prevalent clinical practices regarding resuscitation for severe TBI using vasopressors. Therefore, the aim of this study was to assess the possible association of vasopressor use with mortality in patients with severe TBI, using data from the Japanese Trauma Data Bank (JTDB) registry, which represents the biggest trauma data bank in Japan. Survivors of severe TBI often have cognitive control function deficits $[11,12]$. Therefore, we also analyzed the possibility of reducing the occurrence of cognitive dysfunction through adequate cerebral blood flow using vasopressors.

\section{Methods}

\section{Study design, population, and setting}


This was a nationwide retrospective cohort study conducted using the JTDB database. We included cases registered in the database from January 2004 to December 2018 and patients aged $\geq 16$ years who had a TBI and were transported to a JTDBparticipating hospital. We segregated patients with severe TBI based on the Abbreviated Injury Scale (AIS) code (TBI = 140000) and a Glasgow Coma Scale score of 3-8 on admission. We excluded cases with a maximum head AIS score of 6 (unsurvivable injury) or 9 (unspecified injury), with other critical injuries (AIS scores of $\geq 3$ ), in cardiopulmonary arrest on or before hospital arrival, those who underwent cardiopulmonary resuscitation (i.e., use of adrenaline during cardiopulmonary resuscitation), or had interhospital transport. We also excluded cases with missing outcome data or variables required for propensity score (PS) matching $[13,14]$. This study defined patients in cardiopulmonary arrest as those whose systolic blood pressure was $0 \mathrm{mmHg}$ and/or heart rate was 0 bpm on or before hospital arrival [15].

\section{Japanese Trauma Data Bank}

The JTDB was launched in 2003 by the Japanese Association for the Surgery of Trauma (Trauma Surgery Committee) and the Japanese Association for Acute Medicine (Committee for Clinical Care Evaluation) [15, 16], similar to the trauma databases in North America, Europe, and Oceania. By 2018, 272 major emergency medical institutions across Japan had been registered in the JTDB database [16]. The included hospitals have service levels similar to Level I trauma centers in the United States. Data were collected via the Internet from participating institutions. The physicians and medical assistants who attended the AIS coding course were the main inputters of the data $[15,16]$. The JTDB records trauma patient data including age; sex; mechanism of injury; AIS code (1998 version); Injury Severity Score (ISS); vital signs on hospital arrival; date and time series from hospital arrival to discharge; medical treatments such as interventional radiology, surgery, and computed tomography; complications; and mortality on discharge $[15,16]$. ISS was calculated from the top three AIS scores in nine sites classified using the AIS codes. The data used in this study were the most recent data available in this registry.

\section{Study endpoints}

The primary outcome of this investigation was death on hospital discharge. The secondary outcomes were emergency department (ED) mortality and in-hospital cognitive dysfunction.

\section{Propensity score matching}

In this study, we selected matched PS analysis as the use of vasopressors was not randomly assigned. A logistic regression analysis was performed to estimate a PS for the prediction of vasopressor use from the available predictors. Confounders were carefully selected from previous reports [9, 10,17-20], and clinically important confounders were included to estimate PSs. The probability of receiving vasopressors (PS) for each patient was calculated using multivariable logistic regression analysis based on the following 14 variables: age (continuous variable), sex (male, female), year of onset (2004-2006, 2007-2009, 2010-2012, 2013-2015, 2016-2018), Glasgow Coma Scale score (continuous variable), systolic blood pressure (continuous variable) on admission to the ED, operation indicated for TBI (no, yes), type of injury (blunt, non-blunt), cause of trauma (motor accident, fall, sports, other), type of TBI (isolated TBI, TBI with skull fracture, TBI with intracranial vessel injury, TBI with other head injuries), prehospital intravenous fluid administration (no, yes), use of transfusion in the first 24 hours (no, yes), past medical history of stroke (no, yes), use of anticoagulant or antiplatelet drugs (no, yes), and ISS (continuous variable). We performed a receiver operating characteristic curve analysis with the area under the curve predicting the use of vasopressors in patients with severe TBI. One-to-one pair matching between the non-vasopressor and vasopressor groups was performed by nearest-neighbor matching without replacement, using a caliper width of 0.02 as the standard deviation of PS. Covariate balances before and after matching were checked by comparing standardized mean differences (SMDs). An SMD $<10 \%$ was considered a negligible imbalance between the two groups. In the PS-matched cohort, univariable logistic regression analysis was performed to assess the association between the use of vasopressors and outcomes.

\section{Statistical analysis}

We divided patients into two groups (vasopressor and non-vasopressor). Descriptive data are presented as counts and percentages (categorical variables) or medians and interquartile ranges (continuous variables). Outcomes were evaluated using univariable and multivariable logistic regression analyses to assess the independent effect of vasopressor use. Based on these analyses, we calculated the odds ratios (ORs) and 95\% confidence intervals (Cls). Based on previous reports [9, 10, 17-20], we selected confounders for multivariable logistic regression analysis on the assumption that none were directly affected by the use of 
vasopressors. In the multivariable logistic regression model, we adjusted for the aforementioned 14 variables used in the PS calculation. In addition, subgroup analyses were performed to identify the potential benefits and drawbacks of the use of vasopressors. In each subgroup, a multivariable logistic regression analysis adjusted for the aforementioned variables was performed to assess the independent effect of vasopressor use on mortality on hospital discharge. P for interaction was calculated using the multivariable logistic regression model.

All statistical analyses were conducted using STATA (version 16; StataCorp LP, 4905 Lakeway Drive, College Station, Texas, USA). Statistical significance was defined as a two-sided p value of less than 0.05 or assessed using a $95 \% \mathrm{Cl}$ in all statistical analyses. This manuscript was written based on the STROBE statement for the reporting of cohort and cross-sectional studies [21].

\section{Results}

A total of 10,284 patients were included in the study. Of those, 650 patients $(6.32 \%)$ received vasopressors and 9,634 patients (93.68\%) did not. Figure 1 depicts the flowchart of patients included in this study. The median (interquartile range) age of the included patients was $67(51-79)$ years, and most were men $(69.6 \%[7,159 / 10,284])$. Blunt trauma was the most common type of injury $(95.5 \%[9,819 / 10,284])$. The patient characteristics are summarized in Table 1. There were no significant differences in age, sex, type of trauma, type of TBI, and past medical history (stroke or use of anticoagulant/antiplatelet therapy) between the two groups. While traffic accidents (46.9\% [305/650]) were the leading cause of injury followed by falls $(42.0 \%$ [273/650]) in the vasopressor group, falls $(50.4 \%[4,851 / 9,634])$ caused the most injuries in the non-vasopressor group. Glasgow Coma Scale scores and systolic blood pressure on admission to the ED were significantly lower in the vasopressor group than in the non-vasopressor group (median [interquartile range]) (4 [3-6] vs. 6 [3-7] and 144 [107-172] vs. 151 [128-179] mmHg, respectively). The median (interquartile range) ISS was $25(20-26)$ in the vasopressor group, with the ISS being significantly higher than that in the nonvasopressor group (25 [16-25]) (SMD, 0.336). The vasopressor group had more treatments, including prehospital intravenous infusion (8.5\% [55/650] vs. 4.5\% [429/9,634]), blood transfusion in the first 24 hours $(44.9 \%$ [292/650] vs. 24.3\% [2,345/9,634]) than the non-vasopressor group.

Table 1 shows the baseline characteristics of the PS-matched patients. Following PS matching, 649 patients in each group were included. The area under the receiver operating characteristic curve for PS was 0.73 . The characteristics of PS-matched patients were finely balanced in terms of absolute SMD. 


\begin{tabular}{|c|c|c|c|c|c|c|c|}
\hline & & \multicolumn{3}{|l|}{ All patients } & \multicolumn{3}{|c|}{ PS-matched patients } \\
\hline & & $\begin{array}{l}\text { Non- } \\
\text { vasopressor }\end{array}$ & Vasopressor & & $\begin{array}{l}\text { Non- } \\
\text { vasopressor }\end{array}$ & Vasopressor & \\
\hline & & $N=9,634$ & $N=650$ & SMD & $N=649$ & $N=649$ & SMD \\
\hline Age (years) & & $67(51-79)$ & $69(57-78)$ & 0.092 & $69(54-79)$ & $69(57-78)$ & 0.011 \\
\hline Sex (male) & & $\begin{array}{l}6,732 \\
(69.9 \%)\end{array}$ & $427(65.7 \%)$ & 0.09 & $439(67.6 \%)$ & $427(65.8 \%)$ & 0.039 \\
\hline \multirow[t]{5}{*}{ Year of onset } & $2004-2006$ & $476(4.9 \%)$ & $45(6.9 \%)$ & 0.163 & $51(7.9 \%)$ & $44(6.8 \%)$ & 0.019 \\
\hline & $2007-2009$ & $\begin{array}{l}1,248 \\
(13.0 \%)\end{array}$ & $118(18.2 \%)$ & & $109(16.8 \%)$ & $118(18.2 \%)$ & \\
\hline & $2010-2012$ & $\begin{array}{l}2,265 \\
(23.5 \%)\end{array}$ & $154(23.7 \%)$ & & $157(24.2 \%)$ & $154(23.7 \%)$ & \\
\hline & $2013-2015$ & $\begin{array}{l}3,059 \\
(31.8 \%)\end{array}$ & $177(27.2 \%)$ & & $185(28.5 \%)$ & $177(27.3 \%)$ & \\
\hline & $2016-2018$ & $\begin{array}{l}2,586 \\
(26.8 \%)\end{array}$ & $156(24.0 \%)$ & & $147(22.7 \%)$ & $156(24.0 \%)$ & \\
\hline Type of trauma (blunt) & & $\begin{array}{l}9,198 \\
(95.5 \%)\end{array}$ & $621(95.5 \%)$ & 0.003 & $617(95.1 \%)$ & $620(95.5 \%)$ & 0.022 \\
\hline \multirow[t]{4}{*}{ Cause of trauma } & Motor accident & $\begin{array}{l}3,417 \\
(35.5 \%)\end{array}$ & $305(46.9 \%)$ & 0.185 & $289(44.5 \%)$ & $304(46.8 \%)$ & 0.012 \\
\hline & Fall & $\begin{array}{l}4,851 \\
(50.4 \%)\end{array}$ & $273(42.0 \%)$ & & $298(45.9 \%)$ & $273(42.1 \%)$ & \\
\hline & Sports & $69(0.7 \%)$ & $2(0.3 \%)$ & & $4(0.6 \%)$ & $2(0.3 \%)$ & \\
\hline & Other & $\begin{array}{l}1,297 \\
(13.5 \%)\end{array}$ & $70(10.8 \%)$ & & $58(8.9 \%)$ & $70(10.8 \%)$ & \\
\hline \multirow[t]{4}{*}{ Type of TBI } & Isolated TBI & $\begin{array}{l}5,325 \\
(55.3 \%)\end{array}$ & $283(43.5 \%)$ & 0.091 & $327(50.4 \%)$ & $283(43.6 \%)$ & 0.039 \\
\hline & $\begin{array}{l}\text { w/ Skull } \\
\text { fracture }\end{array}$ & $\begin{array}{l}2,802 \\
(29.1 \%)\end{array}$ & $269(41.4 \%)$ & & $193(29.7 \%)$ & $268(41.3 \%)$ & \\
\hline & $\begin{array}{l}\text { w/ } \\
\text { Cerebrovascular } \\
\text { injury }\end{array}$ & $33(0.3 \%)$ & $11(1.7 \%)$ & & $2(0.3 \%)$ & $11(1.7 \%)$ & \\
\hline & $\begin{array}{l}\text { w/ Other head } \\
\text { injury }\end{array}$ & $\begin{array}{l}1,474 \\
(15.3 \%)\end{array}$ & $87(13.4 \%)$ & & $127(19.6 \%)$ & $87(13.4 \%)$ & \\
\hline SBP on arrival & & $\begin{array}{l}151(128- \\
179)\end{array}$ & $\begin{array}{l}144(107- \\
172)\end{array}$ & 0.291 & $\begin{array}{l}144(120- \\
170)\end{array}$ & $\begin{array}{l}144(107- \\
172)\end{array}$ & 0.051 \\
\hline GCS score on arrival & & $6(3-7)$ & $4(3-6)$ & 0.515 & $4(3-6)$ & $4(3-6)$ & 0.005 \\
\hline Prehospital IV & & $429(4.5 \%)$ & $55(8.5 \%)$ & 0.164 & $52(8.0 \%)$ & $55(8.5 \%)$ & 0.017 \\
\hline Blood transfusion & & $\begin{array}{l}2,345 \\
(24.3 \%)\end{array}$ & $292(44.9 \%)$ & 0.443 & $297(45.8 \%)$ & $291(44.8 \%)$ & 0.019 \\
\hline Operation for TBI & & $\begin{array}{l}3,831 \\
(39.8 \%)\end{array}$ & $272(41.8 \%)$ & 0.042 & $302(46.5 \%)$ & $271(41.8 \%)$ & 0.096 \\
\hline PMH of stroke & & 275 (2.9\%) & $17(2.6 \%)$ & 0.015 & $15(2.3 \%)$ & $17(2.6 \%)$ & 0.02 \\
\hline $\begin{array}{l}\text { Anticoagulant/antiplatelet } \\
\text { therapy }\end{array}$ & & $633(6.6 \%)$ & $32(4.9 \%)$ & 0.071 & $28(4.3 \%)$ & $32(4.9 \%)$ & 0.029 \\
\hline ISS & & $25(16-25)$ & $25(20-26)$ & 0.336 & $25(21-26)$ & $25(20-26)$ & 0.075 \\
\hline
\end{tabular}


The area under the receiver operating characteristic curve of the logistic regression model to calculate a PS was 0.73 .

The results of the multivariable logistic regression analysis and PS matching for the primary outcome are presented in Table 2. Mortality on hospital discharge was higher in the multivariable logistic regression vasopressor group than in the non-vasopressor group (adjusted OR, 5.71; 95\% Cl: 4.56-7.16). For PS-matched patients, mortality on hospital discharge was 81.66\% (530/649) in the vasopressor group and 50.69\% (329/649) in the non-vasopressor group. PS matching analysis illustrated that death on hospital discharge was higher in the vasopressor group than in the non-vasopressor group (OR, 4.33; 95\% Cl: 3.37-5.57).

Table 2. Primary outcome comparisons between patients with and without vasopressor use before and after PS matching

\begin{tabular}{|c|c|c|c|c|c|}
\hline & \multirow[t]{2}{*}{ Total } & \multirow[t]{2}{*}{ Non-vasopressor } & \multirow[t]{2}{*}{ Vasopressor } & \multirow{2}{*}{$\begin{array}{l}\text { Crude OR } \\
(95 \% \mathrm{Cl})\end{array}$} & \multirow{2}{*}{$\begin{array}{l}\text { Adjusted OR } \\
(95 \% \mathrm{Cl})\end{array}$} \\
\hline & & & & & \\
\hline All patients & 10,284 & 9,634 & 650 & & \\
\hline \multirow[t]{2}{*}{ Death at hospital discharge } & $4,405(42.83 \%)$ & $3,874(40.21 \%)$ & $531(81.69 \%)$ & 6.63 & 5.71 \\
\hline & & & & $(5.42-8.13)$ & $(4.56-7.16)$ \\
\hline PS-matched patients & 1,298 & 649 & 649 & & \\
\hline \multirow[t]{2}{*}{ Death at hospital discharge } & $859(66.18 \%)$ & $329(50.69 \%)$ & $530(81.66 \%)$ & 4.33 & \\
\hline & & & & $(3.37-5.57)$ & \\
\hline
\end{tabular}

$\mathrm{Cl}$, confidence interval; OR, odds ratio; PS, propensity score.

Table 3 shows the results of the multivariable logistic regression and PS matching for secondary outcomes. For PS-matched patients, ED mortality in the vasopressor group was higher than that in the non-vasopressor group (8.01\% [52/649] vs. 2.77\% [18/649]) (OR, 3.05; 95\% Cl: 1.77-5.28). There was no significant difference in complications of cognitive disorders between the two groups (5.55\% [36/649] vs. 5.39\% [35/649]) (OR, 0.97; 95\% Cl: 0.60-1.57) (Table 3).

Table 3. Secondary outcome comparisons between patients with and without vasopressor use before and after PS matching

\begin{tabular}{|c|c|c|c|c|c|}
\hline & \multirow[t]{2}{*}{ Total } & \multirow[t]{2}{*}{ Non-vasopressor } & \multirow[t]{2}{*}{ Vasopressor } & \multirow{2}{*}{$\begin{array}{l}\text { Crude OR } \\
(95 \% \mathrm{Cl})\end{array}$} & \multirow{2}{*}{$\begin{array}{l}\text { Adjusted OR } \\
(95 \% \mathrm{Cl})\end{array}$} \\
\hline & & & & & \\
\hline All patients & 10,284 & 9,634 & 650 & & \\
\hline \multirow[t]{2}{*}{ Death at ED } & $198(1.93 \%)$ & $146(1.52 \%)$ & $52(8.00 \%)$ & 5.65 & 3.42 \\
\hline & & & & $(4.07-7.84)$ & $(2.39-4.89)$ \\
\hline \multirow[t]{2}{*}{ Cognitive disorder } & $816(7.93 \%)$ & 781 (8.11\%) & $35(5.38 \%)$ & 0.65 & 0.77 \\
\hline & & & & $(0.46-0.91)$ & $(0.54-1.11)$ \\
\hline PS-matched patients & 1,298 & 649 & 649 & & \\
\hline \multirow[t]{2}{*}{ Death at ED } & 70 (5.39\%) & $18(2.77 \%)$ & $52(8.01 \%)$ & 3.05 & \\
\hline & & & & $(1.77-5.28)$ & \\
\hline \multirow[t]{2}{*}{ Cognitive disorder } & $71(5.47 \%)$ & $36(5.55 \%)$ & $35(5.39 \%)$ & 0.97 & \\
\hline & & & & $(0.60-1.57)$ & \\
\hline
\end{tabular}


$\mathrm{Cl}$, confidence interval; ED, emergency department; OR, odds ratio; PS, propensity score.

Subgroup analysis suggested that the use of vasopressors for severe TBI was associated with higher mortality on hospital discharge for each factor (Fig. 2). As for past medical history, stroke patients had significantly better outcomes than non-stroke patients (adjusted OR [95\% Cl]) (3.33 [95\% Cl: 0.84-13.21] vs. 5.87 [95\% Cl: 4.67-7.39]; $\mathrm{p}=0.039)$.

\section{Discussion}

This was a retrospective cohort study conducted to evaluate the effect of vasopressor use on mortality among patients with severe $\mathrm{TBI}$, using a nationwide trauma database in Japan. With robust analyses to adjust for severity, it was found that the use of vasopressors was significantly associated with higher mortality, not only on hospital discharge but also in the ED. Subgroup analysis also reiterated the same and suggested that the use of vasopressors for severe TBI was associated with higher mortality on hospital discharge in almost all cases.

Hypotension (defined as a systolic blood pressure $<90 \mathrm{mmHg}$ ) is a well-known risk factor associated with the occurrence of secondary cerebral damage and poor outcome, especially after TBI [7-9]. In contrast, the large IMPACT prospective database found that a systolic blood pressure $<120 \mathrm{mmHg}$ is also a strong predictor of unfavorable neurological recovery [22]. Based on these findings, major guidelines or studies, including those of the Brain Trauma Foundation or the SAFE-TBI randomized study in Australia, recommend maintaining a systolic blood pressure $>90 \mathrm{mmHg}$ with a vasopressor after severe TBI $[2,5]$. The purpose of maintaining consistent cerebral perfusion with vasopressors is to prevent hypotensive cerebral ischemia. Further, vasopressors may be used as volume-sparing resuscitating agents to prevent brain edema. However, our study showed that neither mortality nor the occurrence of cognitive dysfunction was improved by the use of vasopressors, suggesting that vasopressors should be avoided in most cases of severe TBI. A similar recommendation was provided by Lund, although the guideline was not supported by strong levels of evidence [23].

Only a few studies have tried to assess whether the use of vasopressors is beneficial for severe TBI [23]. However, a number of studies have focused on which type of vasopressor should be used [24, 25]. Our findings could pave the way for future guidelines regarding the use of vasopressors for the treatment of severe TBI.

The penumbra, the brain tissue surrounding the impacted core of the TBI, becomes particularly vulnerable to cell death by hypoxic insults, and preservation of this area is one of the important objectives for using vasopressors. The overall effects of vasopressor use on the brain are probably a consequence of systemic arterial contraction but are also influenced by other factors such as brain injury, integrity of the blood-brain barrier, and the status of cerebral autoregulation [26]. In the abnormal state of autoregulation after severe TBI, excessive elevation of intracranial pressure favors edema formation by increased capillary hydrostatic pressure across the blood-brain barrier, causing brain herniation [27]. This may also result in unwanted hemodynamic effects, such as intracranial hemorrhage, leading to increased mortality [28, 29]. Additionally, vasopressors cause an array of adverse effects among other organs of the body [30,31]. Catecholamine surge after TBI can lead to peripheral insults induced by the release of proinflammatory substances and result in increased vascular permeability [30]. In this situation, the accentuated proinflammatory response could trigger the development of acute respiratory distress syndrome [31]. Other potential negative systemic side effects of vasopressors include arrhythmia, diuresis, and increased left ventricular afterload.

In patients with severe TBI, low arterial blood pressure, major surgery with bleeding, and blood transfusion can contribute to secondary insults to the brain and aggravate the primary insults and cerebral edema, increasing the risk of developing severe lung injury, or even multiple organ failure. Traditionally, it has been suggested that the clinical effects of brain injuries vary depending on individual characteristics such as sex, age, past medical history, and type of TBI. With multiple confounding factors, planning treatment for TBI is especially challenging. In this study, we used the largest trauma dataset in Japan that allowed us to adjust for confounding factors. To the best of our knowledge, our study included the largest cohort of its kind, to date, that has focused on patients with severe TBI. This study also reveals the utility of vasopressors in some specific conditions (e.g., in patients with TBI with a history of stroke). In cases of stroke, structural cerebrovascular changes may increase resistance; thus, normal cerebral blood flow can be maintained using vasopressors. However, the use of vasopressors in such a subgroup did not reduce mortality at the time of hospital discharge. These results suggest that vasopressors should be avoided in most cases of severe TBI. 
The authors acknowledge a few limitations of this observational study. First, PS matching analysis has the risk of residual selection bias. Some differences in the two groups may still exist, even after PS matching, particularly if data on important confounding factors are not included in the analysis. Second, although the use of vasopressors (mainly catecholamine) for resuscitation was recorded in the JTDB, important information such as the type and dose of vasopressors used and the timing of vasopressor administration was not included, leading to selection bias. Detailed information about the dose, type of vasopressor, mode of administration (bolus and/or continuous), and patients' vital signs when the vasopressor was initiated was not included in the JTDB. However, all TBI patients transported to JTDB-participating hospitals were treated based on the guidelines for the management of severe $\mathrm{TBI}$, which state that vasopressors are recommended to maintain a systolic blood pressure $>110 \mathrm{mmHg}$

[32]. Third, the incidence of cognitive disorders could have been underestimated in our study as the JTDB includes clinical data until hospital discharge, which would largely cater to the acute phase of the injury. Cognitive symptoms after TBI would be accurately evaluated only after recovering from an altered state of consciousness in the acute phase. Additionally, the data included in this study primarily involved cases of blunt trauma, which cannot be extended to penetrating TBI. Lastly, this was an observational study, and there may be other unknown confounding factors. The results of this investigation could not establish causality and remain limited to associations. Ideally, the results should be validated in a randomized study.

Blood pressure augmentation to avoid hypotension has been considered to attenuate secondary cerebral damage. Therefore, the management of blood pressure using vasopressors during the emergent phase and intensive care unit phase is based on lowquality evidence and strong recommendations according to recent guidelines for the management of severe TBI $[5,9,32,33]$. However, our results suggest that vasopressors should be avoided in most cases of severe TBI. Our study has the potential to result in policy and guideline changes for the treatment and management of severe TBI.

\section{Conclusions}

In a Japanese population with severe adult TBI associated with blunt trauma, the use of vasopressors was associated with increased mortality, both on hospital discharge and in the ED. Our results suggest that vasopressors should be avoided in most cases of severe TBI.

\section{Abbreviations}

AIS, Abbreviated Injury Scale; Cl, confidence interval; CPP, cerebral perfusion pressure; ED, emergency department; ISS, Injury Severity Score; JTDB, Japanese Trauma Data Bank; OR, odds ratio; PS, propensity score; SMD, standardized mean difference; TBI, traumatic brain injury.

\section{Declarations}

Ethics approval and consent to participate: This study was approved by the Ethics Committee of Osaka University Graduate School of Medicine (approval number: 16260). Personal identifiers were removed from the JTDB database beforehand; thus, the requirement for informed consent was waived.

Consent for publication: Not applicable.

Availability of data and materials: The data that support the findings of this study are available from the JTDB, but restrictions apply to the availability of these data.

Competing interests: The authors declare that they have no competing interests.

Funding: This work was supported by a Grant-in-Aid for Scientific Research (C) from the Japan Society for the Promotion of Science (18K08886) and a grant from Zenkyoren (National Mutual Insurance Federation of Agricultural Cooperatives) awarded to $\mathrm{SH}$.

Authors' contributions: SH, TS and TK designed the study protocol and wrote the report. SH, TK and AH were responsible for statistical analyses. $\mathrm{OH}$ and TS made substantial modifications to the report. The authors read and approved the final manuscript. 
Acknowledgments: The authors thank the emergency medical service personnel, nurses, neurosurgeons, and emergency medicine physicians who participated in the JTDB. We thank our colleagues from Osaka University Center of Medical Data Science, Advanced Clinical Epidemiology Investigator's Research Project for providing insight and expertise in the research.

\section{References}

1. Maas AIR, Menon DK, Adelson PD, Andelic N, Bell MJ, Belli A, et al. Traumatic brain injury: integrated approaches to improve prevention, clinical care, and research. Lancet Neurol. 2017;16:987-1048.

2. SAFE Study Investigators; Australian and New Zealand Intensive Care Society Clinical Trials Group; Australian Red Cross Blood Service; George Institute for International Health; Myburgh J, Cooper DJ, et al. Saline or albumin for fluid resuscitation in patients with traumatic brain injury. N Engl J Med. 2007;357:874-84.

3. Nichol A, French C, Little L, Haddad S, Presneill J, Arabi Y, et al. Erythropoietin in traumatic brain injury (EPO-TBI): a doubleblind randomised controlled trial. Lancet. 2015;386:2499-506.

4. Farhad K, Khan HM, Ji AB, Yacoub HA, Qureshi Al, Souayah N. Trends in outcomes and hospitalization costs for traumatic brain injury in adult patients in the United States. J Neurotrauma. 2013;30:84-90.

5. Carney N, Totten AM, O'Reilly C, Ullman JS, Hawryluk GW, Bell MJ, et al. Guidelines for the Management of Severe Traumatic Brain Injury, Fourth Edition. Neurosurgery. 2017;80:6-15.

6. McGinn MJ, Povlishock JT. Pathophysiology of traumatic brain injury. Neurosurg Clin N Am. 2016;27:397-407.

7. Stocchetti N, Le Roux P, Vespa P, Oddo M, Citerio G, Andrews PJ, et al. Clinical review: neuromonitoring - an update. Crit Care. 2013;17:201.

8. Corps KN, Roth TL, McGavern DB. Inflammation and neuroprotection in traumatic brain injury. JAMA Neurol. 2015;72:355-62.

9. Carteron L, Taccone FS, Oddo M. How to manage blood pressure after brain injury? Minerva Anestesiol. 2017;83:412-21.

10. Aoki M, Abe T, Saitoh D, Hagiwara S, Oshima K. Use of vasopressor increases the risk of mortality in traumatic hemorrhagic shock: a nationwide cohort study in Japan. Crit Care Med. 2018;46:e1145-51.

11. Miotto EC, Cinalli FZ, Serrao VT, Benute GG, Lucia MC, Scaff M. Cognitive deficits in patients with mild to moderate traumatic brain injury. Arq Neuro Psiquiatr. 2010;68:862-8.

12. Olsen A, Brunner JF, Indredavik Evensen KA, Finnanger TG, Vik A, Skandsen T, et al. Altered cognitive control activations after moderate-to- severe traumatic brain injury and their relationship to injury severity and everyday-life function. Cereb Cortex. 2015;25:2170-80.

13. Butcher N, Balogh ZJ. AIS > 2 in at least two body regions: a potential new anatomical definition of polytrauma. Injury. 2012;43:196-9.

14. Härtl R, Gerber LM, lacono L, Ni Q, Lyons K, Ghajar J. Direct transport within an organized state trauma system reduces mortality in patients with severe traumatic brain injury. J Trauma. 2006;60:1250-6. discussion 1256.

15. Katayama Y, Kitamura T, Hirose T, Kiguchi T, Matsuyama T, Takahashi H, et al. Pelvic angiography is effective for emergency pediatric patients with pelvic fractures: a propensity-score-matching study with a nationwide trauma registry in Japan. Eur J Trauma Emerg Surg. 2019. doi:10.1007/s00068-019-01154-w.

16. Japan Trauma Care and Research. Japan Trauma Data Bank Annual Report 2014-2018. 2019. http://www.jasthp.org/trauma/pdf/jtdb2019e.pdf. Accessed 10 Oct 2020.

17. Hussmann B, Schoeneberg C, Jungbluth P, Heuer M, Lefering R, Maek T, et al. Enhanced prehospital volume therapy does not lead to improved outcomes in severely injured patients with severe traumatic brain injury. BMC Emerg Med. 2019;19:13.

18. Beynon C, Hertle DN, Unterberg AW, Sakowitz OW. Clinical review: traumatic brain injury in patients receiving antiplatelet medication. Crit Care. 2012;16:228.

19. Marshall LF, Marshall SB, Klauber MR, van Berkum Clark M, Eisenberg HM, Jane JA, et al. A new classification of head injury based on computerized tomography. J Neurol Surg. 1991;75:14-20.

20. laccarino C, Schiavi P, Picetti E, Goldoni M, Cerasti D, Caspani M, et al. Patients with brain contusions: predictors of outcome and relationship between radiological and clinical evolution. J Neurol Surg. 2014;120:908-18. 
21. Gallo V, Egger M, McCormack V, Farmer PB, loannidis JP, Kirsch-Volders M, et al. Strengthening the Reporting of OBservational studies in Epidemiology-Molecular Epidemiology STROBE-ME: an extension of the STROBE statement. J Clin Epidemiol. 2011;64:1350-63.

22. Maas Al, Murray GD, Roozenbeek B, Lingsma HF, Butcher I, McHugh GS, et al. Advancing care for traumatic brain injury: findings from the IMPACT studies and perspectives on future research. Lancet Neurol. 2013;12:1200-10.

23. Grände PO. Critical evaluation of the Lund concept for treatment of severe traumatic head injury, 25 years after its introduction. Front Neurol. 2017;8:315.

24. Johnston AJ, Steiner LA, Chatfield DA, Coles JP, Hutchinson PJ, Al-Rawi PG, et al. Effect of cerebral perfusion pressure augmentation with dopamine and norepinephrine on global and focal brain oxygenation after traumatic brain injury. Intensive Care Med. 2004;30:791-7.

25. Sookplung P, Siriussawakul A, Malakouti A, Sharma D, Wang J, Souter MJ, et al. Vasopressor use and effect on blood pressure after severe adult traumatic brain injury. Neurocrit Care. 2011;15:46-54.

26. Rosner MJ, Rosner SD, Johnson AH. Cerebral perfusion pressure: management protocol and clinical results. J Neurol Surg. 1995;83:949-62.

27. Nordström $\mathrm{CH}$. Physiological and biochemical principles underlying volume-targeted therapy - the "Lund concept". Neurocrit Care. 2005;2:83-95.

28. Malhotra AK, Schweitzer JB, Fox JL, Fabian TC, Proctor KG. Cerebral perfusion pressure directed therapy following traumatic brain injury and hypotension in swine. J Neurotrauma. 2003;20:827-39.

29. Chico-Fernández M, Barea-Mendoza JA, Pérez-Bárcena J, García-Sáez I, Quintana-Díaz M, Marina L, et al. Concomitant traumatic brain injury and hemorrhagic shock: outcomes using the Spanish Trauma ICU Registry (RETRAUCI). Am Surg. 2020:0003134820949990.

30. Caplan HW, Cox CS. Resuscitation strategies for traumatic brain injury. Curr Surg Rep. 2019;7.

31. Robertson CS, Valadka AB, Hannay HJ, Contant CF, Gopinath SP, Cormio M, et al. Prevention of secondary ischemic insults after severe head injury. Crit Care Med. 1999;27:2086-95.

32. Guidelines Committee on the Management of Severe Head Injury. Society JN. Japan Society of Neurotraumatology, Japanese Association for the Surgery of Trauma. Guidelines for the Management of Severe Head Injury. 4th ed. Tokyo: Igaku-shoin; 2019.

33. Geeraerts T, Velly L, Abdennour L, Asehnoune K, Audibert G, Bouzat P, et al. Management of severe traumatic brain injury (first 24hours). Anaesth Crit Care Pain Med. 2018;37:171-86.

\section{Figures}




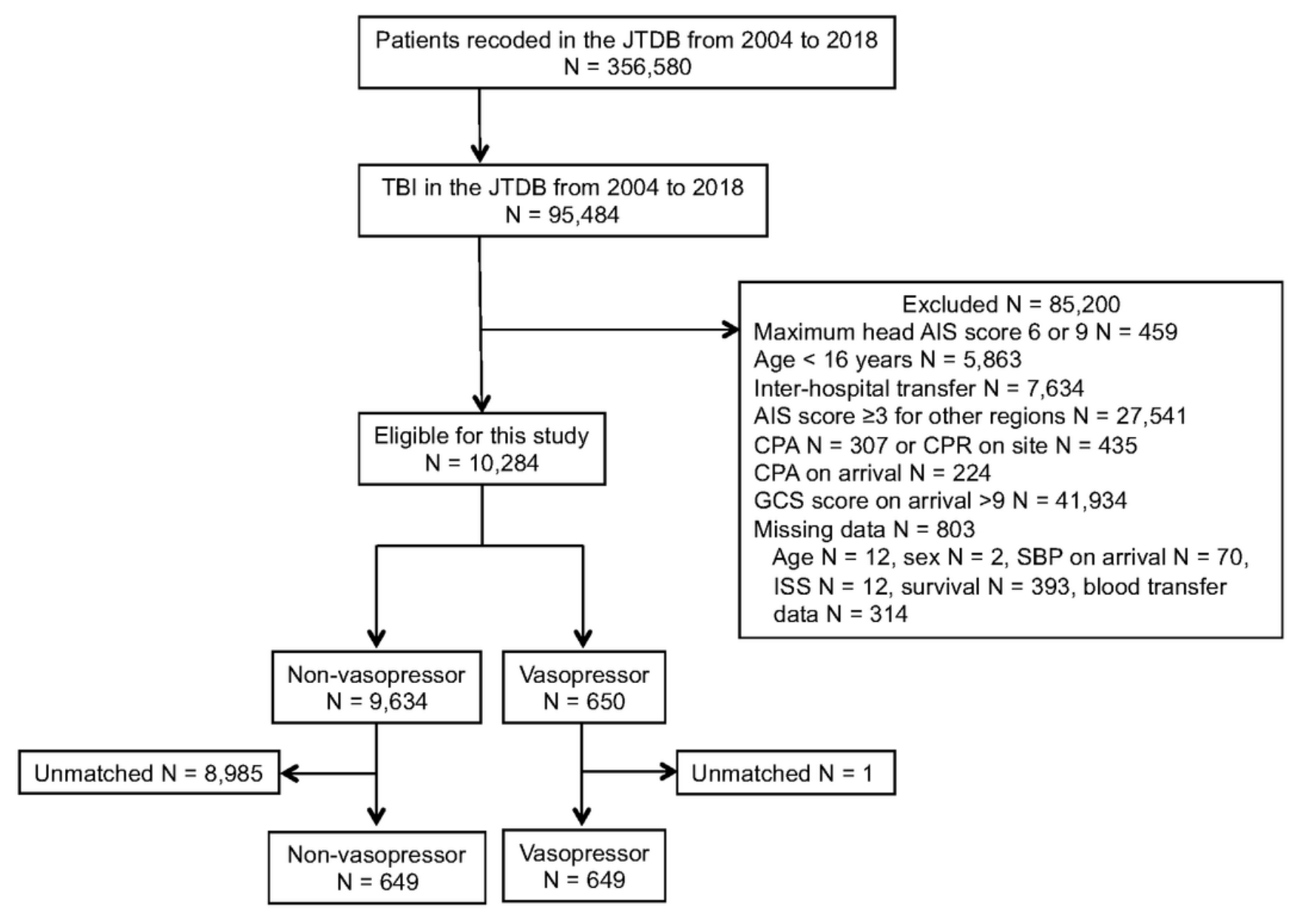

Figure 1

Flowchart of patients included in this study AIS, Abbreviated Injury Scale; CPA, cardiopulmonary arrest; CPR, cardiopulmonary resuscitation; GCS, Glasgow Coma Scale; ISS, Injury Severity Score; JTDB, Japan Trauma Data Bank; SBP, systolic blood pressure; $\mathrm{TBI}$, traumatic brain injury. 


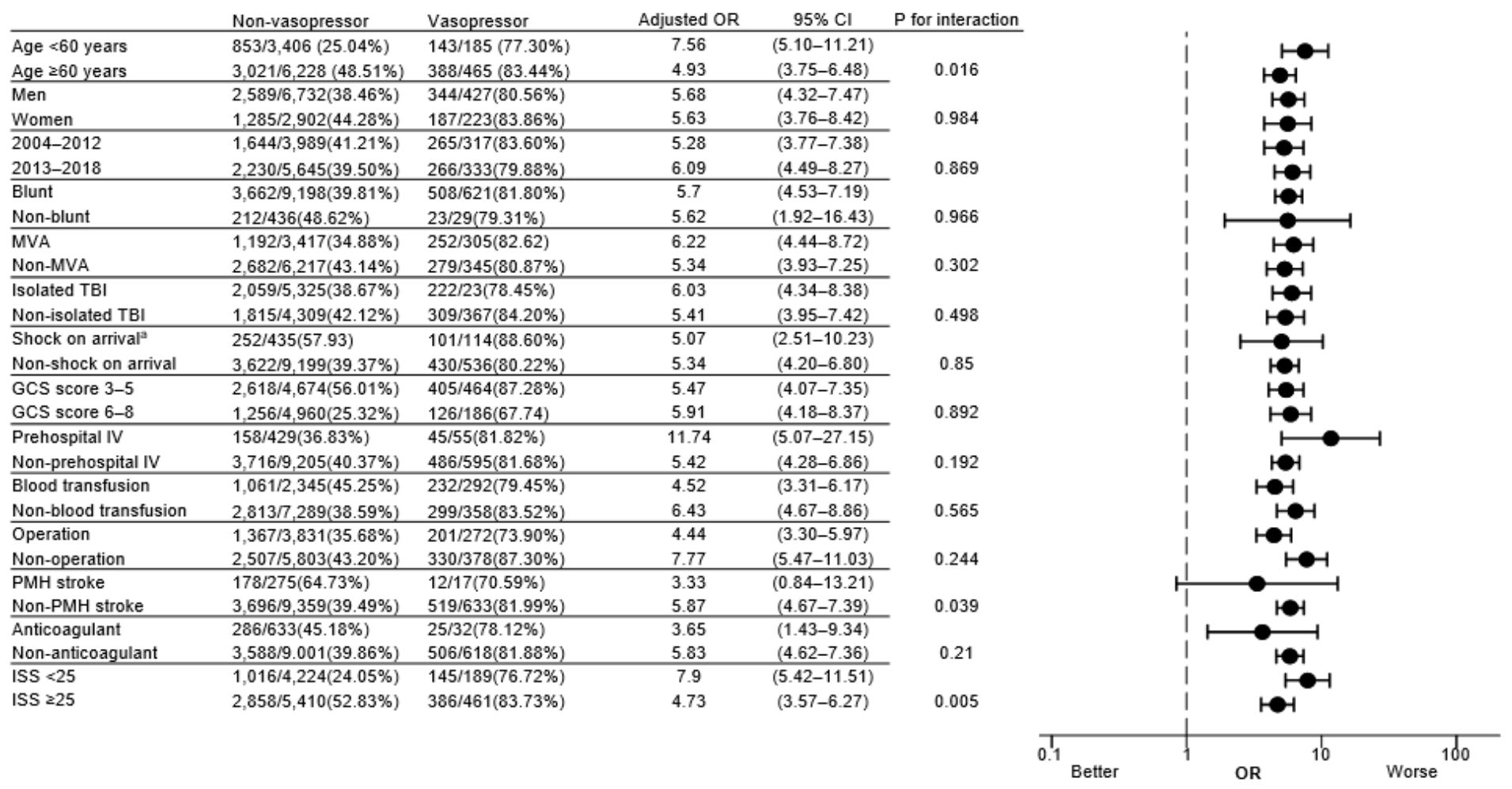

\section{Figure 2}

Subgroup analysis of patients with and without vasopressor use aShock; systolic blood pressure $\leq 90 \mathrm{mmHg}$. Cl, confidence interval; GCS, Glasgow Coma Scale; ISS, Injury Severity Score; IV, intravenous; MVA, motor vehicle accident; OR, odds ratio; PMH, past medical history; TBI, traumatic brain injury. 